\title{
Suppliers Selection in the Presence of both Cardinal and Ordinal Data
}

\author{
Reza Farzipoor Saen \\ Department of Industrial Management, Faculty of Management and Accounting, Islamic Azad \\ University - Karaj Branch, Karaj, Iran, P. O. Box: 31485-313 \\ Tel: 0098 (261) 4418144-6 \\ Fax: 0098 (261) 4418156 \\ E-mail: farzipour@yahoo.com
}

\begin{abstract}
Traditionally, supplier selection models are based on cardinal data with less emphasis on ordinal data. However, with the widespread use of manufacturing philosophies such as Just-In-Time (JIT), emphasis has shifted to the simultaneous consideration of cardinal and ordinal data in supplier selection process. To select the best suppliers in the presence of both cardinal and ordinal data, this paper proposes an innovative method, which is based on Imprecise Data Envelopment Analysis (IDEA). A numerical example demonstrates the application of the proposed method.
\end{abstract}

\section{Keywords: Data envelopment analysis, Supplier selection, Cardinal and ordinal data}

\section{Introduction}

Managing the purchasing task in the supply chain has been a challenge in the last decade for many corporations. The need to gain a global competitive edge on the supply side has increased substantially. Particularly for companies who spend a high percentage of their sales revenue on parts and material supplies, and whose material costs represent a larger portion of total costs, savings from supplies are of particular importance. Moreover, the emphasis on quality and timely delivery in today's globally competitive marketplace adds a new level of complexity to outsourcing and supplier selection decisions. These, strongly urge for a more systematic and transparent method to 
purchasing decision making, especially regarding the area of supplier selection. Selecting the right suppliers significantly reduces the purchasing cost and improves corporate competitiveness, which is why many experts believe that the supplier selection is the most important activity of a purchasing department. Supplier selection is the process by which suppliers are reviewed, evaluated, and chosen to become part of the company's supply chain. Shin et al. (2000) argue that several important factors have caused the current shift to single sourcing or a reduced supplier base. First, multiple sourcing prevents suppliers from achieving the economies of scale based on order volume and learning curve effect. Second, multiple supplier system can be more expensive than a reduced supplier base. For instance, managing a large number of suppliers for a particular item directly increases costs, including the labor and order processing costs to managing multiple source inventories. Meanwhile multiple sourcing lowers overall quality level because of the increased variation in incoming quality among suppliers. Third, a reduced supplier base helps eliminate mistrust between buyers and suppliers due to lack of communication. Fourth, worldwide competition forces firms to find the best suppliers in the world.

Traditionally, supplier selection models are based on cardinal data with less emphasis on ordinal data. However, with the widespread use of manufacturing philosophies such as Just-In-Time (JIT), emphasis has shifted to the simultaneous consideration of cardinal and ordinal data in supplier selection process. This paper proposes a method for selecting the best suppliers in the presence of both cardinal and ordinal data. The objective of this paper is to propose an innovative method for selecting suppliers in the conditions that both ordinal and cardinal data are present (without relying on weight assignment by decision makers).

This paper proceeds as follows. In Section 2, literature review is presented. In Section 3 , the method that selects the suppliers is introduced. Numerical example and concluding remarks are discussed in Sections 4 and 5, respectively.

\section{Literature review}

Some mathematical programming approaches have been used for supplier selection in the past. Karpak et al. (2001) presented one of the "user-friendly" multiple criteria 
decision support systems-Visual Interactive Goal programming (VIG). VIG facilitates the introduction of a decision support vehicle that helps improve the supplier selection decisions. Ghodsypour and O’Brien (2001) developed a mixed integer nonlinear programming model to solve the multiple sourcing problems, which takes into account the total cost of logistics, including net price, storage, transportation and ordering costs. The model should be run $2^{n}$ times for $n$ suppliers that is burdensome. Ross and Droge (2002) measured distribution center productivity in a large scale setting, and identified distribution centers with consistent best performance using facet analysis, and detected performance trends using window analysis of 4 years data. Talluri and Baker (2002) presented a multi-phase mathematical programming approach for effective supply chain design. More specifically, they developed and applied a combination of multi-criteria efficiency models, based on game theory concepts, and linear and integer programming methods. Talluri and Narasimhan (2003) proposed a max-min productivity based approach that derives variability measures of vendor performance, which are then utilized in a nonparametric statistical technique in identifying vendor groups for effective selection. Azoulay-Schwartz et al. (2004) used Gittins indices to optimally select a supplier. To solve the vendor selection problem with multiple objectives, Kumar et al. (2004) applied fuzzy goal programming approach. To incorporate the imprecise aspiration levels of the goals, they formulated a vendor selection problem as a fuzzy mixed integer goal programming that includes three primary goals: minimizing the net cost, minimizing the net rejections, and minimizing the net late deliveries subject to realistic constraints regarding buyer's demand, vendor's capacity, vendor's quota flexibility, purchasing value of items, budget allocation to individual vendor, etc. Ip et al. (2004) described the sub-contractor selection problem by a 0-1 integer programming with non-analytical objective function. Lin and Chen (2004) presented a fuzzy decision making framework for selecting the most favorable strategic supply chain alliance under limited evaluation resources. Hong et al. (2005) proposed a supplier selection method to maintain a continuous supply-relationship with suppliers. They suggested a mathematical programming model that considers the change in supplier's supply capabilities and customer needs over a period in time. Chandra et al. (2005) presented a model for selecting suppliers with geographical location as a critical factor using a Dual-Matrix 
approach. Chang et al. (2006) proposed a Fuzzy Multiple Attribute Decision Making (FMADM) method based on the fuzzy linguistic quantifier. However, their proposed method suffers from two main limitations. First, the proposed method does not consider the inputs. Second, the paper does not discuss whether a decision maker exerts any influence on mental cognition and experiential characteristics when rating the linguistic intervals scale. To select appropriate suppliers, Talluri et al. (2006) suggested a Chance-Constrained Data Envelopment Analysis (CCDEA) approach in the presence of multiple performance measures that are uncertain. Hajidimitriou and Georgiou (2002) presented a quantitative model, based on the Goal Programming (GP) technique, which uses appropriate criteria to evaluate potential candidates and leads to the selection of the optimal partner (supplier). However, one of the GP problems arises from a specific technical requirement. After the purchasing managers specify the goals for each selected criterion (e.g., amount of price, quality level, etc), they must decide on a preemptive priority order of these goals, i.e., determining in which order the goals will be attained. Frequently such an a priori input might not produce an acceptable solution and the priority structure may be altered to resolve the problem once more. In this fashion, it may be possible to generate a solution iteratively that finally satisfies the decision maker. Unfortunately, the number of potential priority reorderings may be very large. A supplier selection problem with five factors has up to 120 priority reorderings. Going through such a laborious process would be costly and inefficient. To take into account both cardinal and ordinal data in supplier selection, Wang et al. (2004) developed an integrated Analytic Hierarchy Process (AHP) and Preemptive Goal Programming (PGP) based methodology. However, their methodology has three main weaknesses. First subjectivity of AHP is a weakness. Second AHP could not include interrelationship within the criteria in the model. Third as mentioned before, the solution process of GP is computational burden. Cakravastia et al. (2002) developed an analytical model of the supplier selection process in designing a supply chain network. The constraints on the capacity of each potential supplier are considered in the process. To decide the total ranking of the suppliers, Liu and Hai (2005) compared the weighted sum of the selection number of rank vote, after determining the weights in a selected rank. They presented a novel weighting procedure in place of pairwise comparison of AHP for selecting 
suppliers. They provided a simpler method than AHP that is called voting analytic hierarchy process, but which do not lose the systematic approach of deriving the weights to be used and for scoring the performance of suppliers. Sha and Che (2006) presented a multi-phased mathematical approach called the Hybrid Multi-phased-based Genetic Algorithm (HMGA) for network design of supply chain. From the point of network design, the important issues are to find suitable and quality companies, and to decide upon an appropriate production/distribution strategy. It is based on various methodologies that embrace Genetic Algorithms (GAs), AHP, and the Multi-Attribute Utility Theory (MAUT) to simultaneously satisfy the preferences of suppliers and customers at each level of the supply chain network. Xia and Wu (in press) proposed an integrated approach of AHP improved by rough sets theory and multi-objective mixed integer programming to simultaneously determine the number of suppliers to employ and the order quantity allocated to these suppliers in the case of multiple sourcing, multiple products, with multiple criteria and with supplier's capacity constraints. Choy et al. (2002) presented an Intelligent Supplier Management Tool (ISMT) using the Case-Based Reasoning (CBR) and Neural Network (NN) techniques to select and benchmark suppliers. Dulmin and Mininno (2003) presented a proposal for applying a decision model to the final vendor-rating phase of a process of supplier selection. Their model uses a Multiple Criteria Decision Aid (MCDA) technique (PROMETHEE 1 and 2), with a high-dimensional sensitivity analysis approach. They tried to explain how an outranking method and PROMETHEE/GAIA techniques, provides powerful tools to rank alternatives and analyzed the relations between criteria or between decision makers. Humphreys et al. (2003) introduced a framework for integrating environmental factors into the supplier selection process. They developed a decision support tool that helps companies to integrate environmental criteria into their supplier selection process. Subsequently, a framework of the supplier selection process that incorporates environmental performance is developed. In their framework, the user should give weightings to the environmental categories in order to represent its importance in the analysis. Chen et al. (2006) presented a fuzzy decision making approach to deal with the supplier selection problem in supply chain system. They used linguistic values to assess the ratings and weights for the criteria. These linguistic ratings can be expressed in 
trapezoidal or triangular fuzzy numbers. Then, a hierarchy Multiple Criteria Decision Making (MCDM) model based on fuzzy sets theory is proposed to deal with the supplier selection problems in the supply chain system. According to the concept of the Technique for Order Preference by Similarity to Ideal Solution (TOPSIS), a closeness coefficient is defined to determine the ranking order of all suppliers by calculating the distances to the both Fuzzy Positive Ideal Solution (FPIS) and Fuzzy Negative Ideal Solution (FNIS) simultaneously.

However, all of the abovementioned references mainly deal with cardinal data on the one hand, and subjective weight assignment on the other hand. A technique that can deal with both ordinal and cardinal data and not relying on weight assignment by decision makers is needed to better model such situation.

To the best of author's knowledge, there is not any reference that deals with supplier selection in the conditions that both ordinal and cardinal data are present.

\section{Proposed method for suppliers selection}

Data Envelopment Analysis (DEA) ${ }^{1}$ proposed by Charnes et al. (1978) (CCR model) and developed by Banker et al. (1984) (BCC model) is an approach for evaluating the efficiencies of Decision Making Units (DMUs). This evaluation is generally assumed to be based on a set of cardinal (quantitative) output and input factors. In many real world applications (especially supplier selection problems), however, it is essential to take into account the existence of ordinal (qualitative) factors when rendering a decision on the performance of a DMU. Very often, it is the case that for a factor such as supplier reputation, one can, at most, provide a ranking of the DMUs from best to worst relative to this attribute. The capability of providing a more precise, quantitative measure reflecting such a factor is generally beyond the realm of reality. In some situations, such factors can be legitimately quantified, but very often; such quantification may be superficially forced as a modeling convenience. In situations such as that described, the data for certain influence factors (inputs and outputs) might better be represented as rank positions in an ordinal, rather than numerical sense. Refer again to the supplier reputation example. In certain circumstances, the information available may permit one to provide a complete rank ordering of the DMUs on such a factor. Therefore, the data may be imprecise. To 
deal with imprecise data in DEA, Imprecise Data Envelopment Analysis (IDEA) models and methods have been developed. When imprecision is taken into consideration, the associated DEA model becomes nonlinear, which makes its solution procedure difficult.

Suppose there is a set of $n$ peer DMUs, $\left\{\mathrm{DMU}_{j}: j=1,2, \ldots, n\right\}$, which produce multiple outputs $y_{r j}(r=1,2, \ldots, s)$, by utilizing multiple inputs $x_{i j}(i=1,2, \ldots, m)$. When a $\mathrm{DMU}_{o}$ is under evaluation by the CCR model, there is: $\max \pi_{o}=\sum_{r=1}^{s} \mu_{r} y_{r o}$

s.t.

$$
\begin{aligned}
& \sum_{r=1}^{s} \mu_{r} y_{r j}-\sum_{i=1}^{m} w_{i} x_{i j} \leq 0 \quad \forall j, \\
& \sum_{i=1}^{m} w_{i} x_{i o}=1, \\
& \mu_{r}, w_{i} \geq 0 \quad \forall r, i .
\end{aligned}
$$

where $\mu_{r}$ is weight of the rth output and $w_{i}$ is weight of the ith input.

Cooper et al. (1999) and Kim et al. (1999) discussed that some of the outputs and inputs are imprecise data in the forms of bounded data, ordinal data, and ratio bounded data as follows.

\section{Bounded data}

$\underline{y}_{r j} \leq y_{r j} \leq \bar{y}_{r j}$ and $\underline{x}_{i j} \leq x_{i j} \leq \bar{x}_{i j}$ for $r \in B O, \quad i \in B I$,

where $\underline{y}_{r j}$ and $\underline{x}_{i j}$ are the lower bounds and $\bar{y}_{r j}$ and $\bar{x}_{i j}$ are the upper bounds, and BO and BI represent the associated sets containing bounded outputs and bounded inputs, respectively.

Weak ordinal data

$y_{r j} \leq y_{r k}$ and $x_{i j} \leq x_{i k}$ for $j \neq k, \quad r \in D O, \quad i \in D I$,

or, to simplify the presentation, 
$y_{r 1} \leq y_{r 2} \leq \cdots \leq y_{r k} \leq \cdots \leq y_{r n} \quad(r \in D O)$,

$x_{i 1} \leq x_{i 2} \leq \cdots \leq x_{i k} \leq \cdots \leq x_{i n} \quad(i \in D I)$,

where DO and DI represent the associated sets containing weak ordinal outputs and inputs, respectively.

Strong ordinal data

$y_{r 1}<y_{r 2}<\ldots<y_{r k}<\ldots<y_{r n} \quad(r \in \mathrm{SO})$,

$x_{i 1}<x_{i 2}<\ldots<x_{i k}<\ldots<x_{i n} \quad(i \in \mathrm{SI})$,

where SO and SI represent the associated sets containing strong ordinal outputs and inputs, respectively.

Ratio bounded data

$$
\begin{array}{ll}
L_{r j} \leq \frac{y_{r j}}{y_{r j_{o}}} \leq U_{r j} & \left(j \neq j_{o}\right) \quad(r \in R O), \\
G_{i j} \leq \frac{X_{i j}}{X_{i j_{o}}} \leq H_{i j} & \left(j \neq j_{o}\right) \quad(i \in R I),
\end{array}
$$

where $L_{r j}$ and $G_{i j}$ represent the lower bounds, and $U_{r j}$ and $H_{i j}$ represent the upper bounds. $\mathrm{RO}$ and RI represent the associated sets containing ratio bounded outputs and inputs, respectively.

If (2)-(8) are incorporated into model (1), there will be: 
$\max \pi_{o}=\sum_{r=1}^{s} \mu_{r} y_{r o}$

s.t.

$$
\begin{aligned}
& \sum_{r=1}^{s} \mu_{r} y_{r j}-\sum_{i=1}^{m} w_{i} x_{i j} \leq 0, \quad j=1, \cdots, n \\
& \sum_{i=1}^{m} w_{i} x_{i o}=1 \\
& \left(x_{i j}\right) \in \Theta_{i}^{-} \\
& \left(y_{r j}\right) \in \Theta_{r}^{+}, \\
& \mu_{r}, w_{i} \geq 0
\end{aligned}
$$

where $\left(x_{i j}\right) \in \Theta_{i}^{-}$and $\left(y_{r j}\right) \in \Theta_{r}^{+}$represent any or all of (2)-(8).

Obviously, model (9) is nonlinear and non-convex, because some of the outputs and inputs become unknown decision variables. Since model (9) is nonlinear and non-convex, consequently local optimum is produced and we cannot be sure whether this is the global optimum or not.

To convert model (9) into the linear program, Zhu (2003) developed a simple approach by defining

$$
\begin{array}{ll}
X_{i j}=w_{i} x_{i j} & \forall i, j, \\
Y_{r j}=\mu_{r} y_{r j} & \forall r, j .
\end{array}
$$

Then model (9) can be converted into the following linear program:

$$
\pi_{o}^{*}=\max \quad \sum_{r=1}^{s} Y_{r o}
$$

s.t.

$$
\begin{aligned}
& \sum_{r=1}^{s} Y_{r j}-\sum_{i=1}^{m} X_{i j} \leq 0, \quad j=1, \cdots, n \\
& \sum_{i=1}^{m} X_{i o}=1, \\
& X_{i j} \in \tilde{D}_{i}^{-}, \\
& Y_{r j} \in \tilde{D}_{r}^{+}, \quad \\
& X_{i j} \geq 0 \quad \forall i, \\
& Y_{r j} \geq 0 \quad \forall r,
\end{aligned}
$$

where $\Theta_{r}^{+}$and $\Theta_{i}^{-}$are transformed into $\tilde{D}_{r}^{+}$and $\tilde{D}_{i}^{-}$with: 
1. bounded data: $\underline{y}_{r j} \mu_{r} \leq Y_{r j} \leq \mu_{r} \bar{y}_{r j}, \quad w_{i} \underline{X}_{i j} \leq X_{i j} \leq w_{i} \bar{X}_{i j}$;

2. ordinal data: $Y_{r j} \leq Y_{r k}$ and $X_{i j} \leq X_{i k} \forall j \neq k \quad$ for some $r, i$;

3. ratio bounded data: $L_{r j} \leq \frac{Y_{r j}}{Y_{r j_{o}}} \leq U_{r j}$ and $G_{i j} \leq \frac{X_{i j}}{X_{i j_{o}}} \leq H_{i j} \quad\left(j \neq j_{o}\right)$;

4. cardinal data: $Y_{r j}=\hat{y}_{r j} \mu_{r}$ and $X_{i j}=w_{i} \hat{x}_{i j}$, where $\hat{y}_{r j}$ and $\hat{x}_{i j}$ represent cardinal data.

In the next section, a numerical example is presented.

\section{Numerical example}

The data set for this example is partially taken from Talluri and Baker (2002) and contains specifications on 18 suppliers. The cardinal input considered is Total Cost of shipments (TC) ${ }^{2}$. Supplier Reputation (SR) is included as a qualitative input while Number of Bills received from the supplier without errors (NB) will serve as the bounded data output. SR is an intangible factor that is not usually explicitly included in evaluation model for supplier. This qualitative variable is measured on an ordinal scale. Table 1 depicts the supplier's attributes. 
Table 1. Related attributes for 18 suppliers and efficiency scores

\begin{tabular}{|c|c|c|c|c|}
\hline \multirow{2}{*}{$\begin{array}{c}\text { Supplier } \\
\text { No. } \\
\text { (DMU) }\end{array}$} & \multicolumn{2}{|c|}{ Inputs } & Output & \multicolumn{2}{|c|}{} \\
\cline { 2 - 4 } & $x_{1 j}$ & $x_{2 j}$ & $y_{1 j}$ & Efficiency \\
\hline 1 & 253 & 5 & {$[50,65]$} & .722 \\
\hline 2 & 268 & 10 & {$[60,70]$} & .7 \\
\hline 3 & 259 & 3 & {$[40,50]$} & .556 \\
\hline 4 & 180 & 6 & {$[100,160]$} & 1 \\
\hline 5 & 257 & 4 & {$[45,55]$} & .611 \\
\hline 6 & 248 & 2 & {$[85,115]$} & 1 \\
\hline 7 & 272 & 8 & {$[70,95]$} & .95 \\
\hline 8 & 330 & 11 & {$[100,180]$} & 1 \\
\hline 9 & 327 & 9 & {$[90,120]$} & 1 \\
\hline 10 & 330 & 7 & {$[50,80]$} & .8 \\
\hline 11 & 321 & 16 & {$[250,300]$} & 1 \\
\hline 12 & 329 & 14 & {$[100,150]$} & .75 \\
\hline 13 & 281 & 15 & {$[80,120]$} & .66 \\
\hline 14 & 309 & 13 & {$[200,350]$} & 1 \\
\hline 15 & 291 & 12 & {$[40,55]$} & .55 \\
\hline 16 & 334 & 17 & {$[75,85]$} & .34 \\
\hline 17 & 249 & 1 & {$[90,180]$} & 1 \\
\hline 18 & 216 & 18 & {$[90,150]$} & .892 \\
\hline
\end{tabular}

* Ranking such that $18 \equiv$ highest rank, $\ldots, 1 \equiv$ lowest $\operatorname{rank}\left(x_{2,18}>x_{2,16} \ldots>x_{2,17}\right)$

Now the transformation process involved in model (11), is illustrated. That is, $\Theta_{1}^{-}=\left\{x_{11}=253 ; x_{12}=268 ; x_{13}=259 ; \ldots ; x_{118}=216\right\} \quad$ (cardinal data) $\Theta_{2}^{-}=\left\{x_{218} \geq x_{216} \geq \cdots \geq x_{217}\right\} \quad$ (ordinal data) $\Theta_{1}^{+}=\left\{50 \leq y_{11} \leq 65 ; 60 \leq y_{12} \leq 70 ; 40 \leq y_{13} \leq 50 ; \ldots ; 90 \leq y_{118} \leq 150\right\}$ (bounded data)

By using $(10), \Theta_{1}^{-}, \Theta_{2}^{-}$, and $\Theta_{1}^{+}$are, respectively, transformed into 
$\widetilde{D}_{1}^{-}=\left\{X_{11}=253 w_{1} ; \quad X_{12}=268 w_{1} ; \quad X_{13}=259 w_{1} ; \cdots ; \quad X_{118}=216 w_{1}\right\}$

$\tilde{D}_{2}^{-}=\left\{X_{218} \geq X_{216} \geq \cdots \geq X_{217}\right\}$

$\tilde{D}_{1}^{+}=\left\{50 \mu_{1} \leq Y_{11} \leq 65 \mu_{1} ; 60 \mu_{1} \leq Y_{12} \leq 70 \mu_{1} ; 40 \mu_{1} \leq Y_{13} \leq 50 \mu_{1} ; \cdots ; 90 \mu_{1} \leq Y_{118} \leq 150 \mu_{1}\right\}$

Applying model (11), the efficiency scores of suppliers (DMUs) have been presented in the last column of Table 1.

Model (11) identified suppliers 4, 6, 8, 9, 11, 14, and 17 to be efficient with a relative efficiency score of 1 . The remaining 11 suppliers with relative efficiency scores of less than 1 are considered inefficient. Therefore, decision maker can choose one or more of these efficient suppliers.

\section{Concluding remarks}

Many practitioners and researchers have presented the advantages of supply chain management. In order to increase the competitive advantage, many companies consider that a well-designed and implemented supply chain system is an important tool. Under this condition, building on the closeness and long-term relationships between buyers and suppliers is critical success factor to establish the supply chain system. Therefore, supplier selection problem becomes the most important issue to implement a successful supply chain system. To select the most efficient suppliers in the conditions that both ordinal and cardinal factors are present, a methodology was introduced.

The results of this paper can be applied from both a buyer's and supplier's perspective. The buyer can use it as a tool in selecting the "best" supplier. The supplier can use these results from a marketing perspective. A specific supplier, who achieves a high mean score, when compared to the other suppliers, can use these results for promoting their product. On the other hand, if a particular supplier is poorly performing, then the supplier can use the analysis for benchmarking purposes. This result may mean that the supplier must provide better performance levels at the same input.

The problem considered in this study is at initial stage of investigation and much further researches can be done based on the results of this paper. Some of them are as follows: 
Similar research can be repeated for dealing with ordinal data and bounded data by fuzzy sets. The other research can be accomplished for suppliers ranking in the presence of qualitative data, imprecise data, and stochastic data. Other potential extension to the methodology includes the case that some of the suppliers are slightly non-homogeneous. One of the assumptions of all the classical models of DEA is based on complete homogeneity of DMUs (suppliers), whereas this assumption in many real applications cannot be generalized. In other words, some inputs and/or outputs are not common for all the DMUs occasionally. Therefore, there is a need to a model that deals with these conditions. To compare the results of performance of proposed method with fuzzy DEA will be another research topic.

\section{References}

Azoulay-Schwartz R., Kraus S., Wilkenfeld J., Exploitation vs. Exploration: Choosing a Supplier in an Environment of Incomplete Information, Decision Support Systems, Vol. 38, No. 1 (2004) pp. 1-18.

Banker R. D., Charnes A., Cooper W. W., Some Methods for Estimating Technical and Scale Inefficiencies in Data Envelopment Analysis, Management Science, Vol. 30, No. 9 (1984) pp. 1078-1092.

Cakravastia A., Toha I. S., Nakamura N., A Two-Stage Model for the Design of Supply Chain Networks, International Journal of Production Economics, Vol. 80, No. 3 (2002) pp. 231-248.

Chandra S., Chen B., Chan W. M., Supplier Selection Using Dual-Matrix Approach in a JIT System, Proceedings of 14th International Conference for the International Association of Management of Technology, (2005) pp. 1-6. 
Chang S. L., Wang R. C., Wang S. Y., Applying Fuzzy Linguistic Quantifier to Select Supply Chain Partners at Different Phases of Product Life Cycle, International Journal of Production Economics, Vol. 100, No. 2 (2006) pp. 348-359.

Charnes A., Cooper W. W., Rhodes E., Measuring the Efficiency of Decision Making Units, European Journal of Operational Research, Vol. 2, No. 6 (1978) pp. 429-444.

Chen C. T., Lin C. T., Huang S. F., A Fuzzy Approach for Supplier Evaluation and Selection in Supply Chain Management, International Journal of Production Economics, Vol. 102, No. 2 (2006) pp. 289-301.

Choy K. L., Lee W. B., Lo V., An Intelligent Supplier Management Tool for Benchmarking Suppliers in Outsource Manufacturing, Expert Systems with Applications, Vol. 22, No. 3 (2002) pp. 213-224.

Cooper W. W., Park K.S., Yu G., IDEA and AR-IDEA: Models for Dealing with Imprecise Data in DEA, Management Science, Vol. 45, No. 4 (1999) pp. 597-607.

Dulmin R., Mininno V., Supplier Selection Using a Multi-Criteria Decision Aid Method, Journal of Purchasing and Supply Management, Vol. 9, No. 4 (2003) pp. 177-187.

Ghodsypour S. H., O'Brien C., The Total Cost of Logistics in Supplier Selection, Under Conditions of Multiple Sourcing, Multiple Criteria and Capacity Constraint, International Journal of Production Economics, Vol. 73, No. 1 (2001) pp. 15-27.

Hajidimitriou Y. A., Georgiou A. C., A Goal Programming Model for Partner Selection Decisions in International Joint Ventures, European Journal of Operational Research, Vol. 138, No. 3 (2002) pp. 649-662. 
Hong G. H., Park S. C., Jang D. S., Rho H. M., An Effective Supplier Selection Method for Constructing a Competitive Supply-Relationship, Expert Systems with Applications, Vol. 28, No. 4 (2005) pp. 629-639.

Humphreys P. K., Wong Y. K., Chan F. T. S., Integrating Environmental Criteria into the Supplier Selection Process, Journal of Materials Processing Technology, Vol. 138, No. 13 (2003) pp. 349-356.

Ip W. H., Yung K. L., Wang D., A Branch and Bound Algorithm for Sub-Contractor Selection in Agile Manufacturing Environment, International Journal of Production Economics, Vol. 87, No. 2 (2004) pp. 195-205.

Karpak B., Kumcu E., Kasuganti R. R., Purchasing Materials in the Supply Chain: Managing a Multi-Objective Task, European Journal of Purchasing \& Supply Management, Vol. 7, No. 3 (2001) pp. 209-216.

Kim S. H., Park C. G., Park K. S., An Application of Data Envelopment Analysis in Telephone Offices Evaluation with Partial data, Computers \& Operations Research, Vol. 26, No. 1 (1999) pp. 59-72.

Kumar M., Vrat P., Shankar R., A Fuzzy Goal Programming Approach for Vendor Selection Problem in a Supply Chain, Computers \& Industrial Engineering, Vol. 46, No. 1 (2004) pp. 69-85.

Lin C. W. R., Chen H. Y. S., A Fuzzy Strategic Alliance Selection Framework for Supply Chain Partnering under Limited Evaluation Resources, Computers In Industry, Vol. 55, No. 2 (2004) pp. 159-179.

Liu F. F., Hai H. L., The Voting Analytic Hierarchy Process Method for Selecting Supplier, International Journal of Production Economics, Vol. 97, No. 3 (2005) pp. 308317. 
Ross A., Droge C., An Integrated Benchmarking Approach to Distribution Center Performance Using DEA Modeling, Journal of Operations Management, Vol. 20, No. 1 (2002) pp. 19-32.

Sha D., Che Z., Supply Chain Network Design: Partner Selection and Production/Distribution Planning using a Systematic Model, Journal of the Operational Research Society, Vol. 57, No. 1 (2006) pp. 52-62.

Shin H., Collier D. A., Wilson D. D., Supply Management Orientation and Supplier/Buyer Performance, Journal of Operations Management, Vol. 18, No. 3 (2000) pp. 317-333.

Talluri S., Baker R. C., A Multi-Phase Mathematical Programming Approach for Effective Supply Chain Design, European Journal of Operational Research, Vol. 141, No. 3 (2002) pp. 544-558.

Talluri S., Narasimhan R., Vendor Evaluation with Performance Variability: A Max-Min Approach, European Journal of Operational Research, Vol. 146, No. 3 (2003) pp. 543552.

Talluri S., Narasimhan R., Nair A., Vendor Performance with Supply Risk: a ChanceConstrained DEA Approach, International Journal of Production Economics, Vol. 100, No. 2 (2006) pp. 212-222.

Wang G., Huang S. H., Dismukes J. P., Product-Driven Supply Chain Selection Using Integrated Multi-Criteria Decision-Making Methodology, International Journal of Production Economics, Vol. 91, No. 1 (2004) pp. 1-15.

Xia W., Wu Z., Supplier Selection with Multiple Criteria in Volume Discount Environments, Omega, in press. 
Zhu J., Imprecise Data Envelopment Analysis (IDEA): A Review and Improvement with an Application, European Journal of Operational Research, Vol. 144, No. 3 (2003) pp. 513-529.

${ }^{1}$ Since the DEA models have become common knowledge, the readers are directed to the references.

${ }^{2}$ The inputs and outputs selected in this paper are not exhaustive by any means, but are some general measures that can be utilized to evaluate suppliers. In an actual application of this methodology, decision makers must carefully identify appropriate inputs and outputs measures to be used in the decision making process. 